\title{
Peningkatan iptek guru TK melalui penggunaan aplikasi zoom untuk pembelajaran berbasis daring
}

\author{
Nonik Indrawatiningsih"*, Luthfi Hakim² \\ 1Universitas PGRI Wiranegara, Pasuruan, Indonesia, email: nonikPhy.D@gmail.com \\ 2Universitas Islam Majapahit, Mojokerto, Indonesia, email: hakimunim@gmail.com \\ *Koresponden penulis
}

\section{Info Artikel}

Diajukan: 01 Feb 2021

Diterima: 21 Jun 2021

Diterbitkan: 29 Jun 2021

Keywords:

iptek; training; online

learning; zoom aplication

\section{Kata Kunci:}

iptek; pelatihan;

pembelajaran berbasis

daring; aplikasi zoom

\section{Lisensi:}

cc-by-sa

\begin{abstract}
The role of technology (science and technology) is currently very much needed as a means of conducting online learning. One of the technologies that can be applied in bold learning is the Zoom Meeting Cloud application. The purpose of this service is to provide training to kindergarten teachers in operating the Zoom Cloud Meeting application as a bold learning tool. The method used is in the form of training. The subject of the study are 6 orders of people and is a kindergarten teacher. The performance indicator in the implementation of this service program is $70 \%$ of participants can operate the Zoom Cloud Meeting application. Based on the results of the training, it shows that the training participants can be categorized into 2, namely participants who succeed in achieving 5 indicators (100\%) with 2 participants and participants who reach 4 indicators (80\%) with 4 participants in using the Zoom Cloud Meeting application. From this training the participants were greatly helped because the previous participants had not been able to operate the Zoom Cloud Meeting application but after the training participants were able to run the Zoom Cloud Meeting application.
\end{abstract}

\begin{tabular}{l}
\hline Abstrak \\
\hline Peran teknologi (IPTEK) saat ini sangat dibutuhkan sebagai sarana \\
dalam melakukan pembelajaran daring. Salah satu teknologi yang \\
dapat diaplikasikan dalam pembelajaran daring adalah aplikasi Zoom \\
Meeting Cloud. Tujuan dari pelaksanaan pengabdian ini adalah untuk \\
memberikan pelatihan kepada Guru TK dalam mengoperasikan \\
aplikasi Zoom Cloud Meeting sebagai sarana pembelajaran daring. \\
Metode yang digunakan dalam bentuk pelatihan. Subjek berjumlah 6 \\
orang dan merupakan guru TK. Indikator keberhasilan dalam \\
pelaksanaan program pengabdian ini adalah 70\% peserta dapat \\
mengoperasikan aplikasi Zoom Cloud Meeting. Berdasarkan hasil \\
pelatihan menunjukkn bahwa kemampuan peserta pelatihan dapat \\
dikatagorikan menjadi 2 , yaitu peserta yang berhasil mencapai 5 \\
indikator (100\% bisa) dengan jumlah 2 peserta dan peserta yang \\
mencapai 4 indikator (80\% bisa) dengan jumlah 4 peserta dalam \\
penggunaan aplikasi Zoom Cloud Meeting. Dari pelatihan ini peserta \\
sangat terbantu karena sebelumnya peserta belum mampu \\
mengoperasikan aplikasi Zoom Cloud Meeting tetapi setelah pelatihan \\
peserta menjadi mampu mengoperasikan aplikasi Zoom Cloud \\
Meeting.
\end{tabular}




\section{PENDAHULUAN}

Bagian Proses pembelajaran pada hakikatnya adalah proses interaksi dua arah yang melibatkan komunikasi antara guru dengan siswa secara tatap muka di suatu kelas (Puspitasari \& Hidayatullah, 2020). Akan tetapi, dengan adanya pandemi Covid-19 sejak bulan Maret tahun 2020 menyebabkan proses pembelajaran di sekolah-sekolah secara tatap muka terpaksa dihentikan sementara. Hal tersebut dikarenakan untuk mencegah penularan Covid-19 secara massif. Kemendikbud memberikan instruksi sekolah-sekolah untuk menyelenggarakan pembelajaran jarak jauh (Daring) dan menyarankan siswa untuk belajar dari rumah masing-masing (Noor, 2011) sehingga guru dipaksa untuk kreatif dalam mengelola pembelajaran meskipun tidak tatap muka melainkan pembelajaran melalui daring. Pada saat yang seperti inilah peran teknologi sangat dibutuhkan sebagai sarana dalam melakukan pembelajaran daring. Penggunaan teknologi memiliki kontribusi besar di dunia pendidikan, termasuk di dalamnya adalah pencapaian tujuan pembelajaran secara daring (Korucu \& Alkan, 2011; Rahman, 2020; Lestari \& Wirasty, 2019).

Berbagai Media juga dapat menunjang pelaksanaan proses pembelajaran daring. Misalnya Google Classroom, Edmodo, dan Schoology (Sicat \& Ed, 2015; Iftakhar, 2016; Rahman, 2020), dan aplikasi pesan instan seperti WhatsApp (So, 2016) dengan cara memberikan informasi atau tugastugas yang seharusnya dikerjakan oleh siswa kemudian tugas tersebut dikirimkan melalui WhatsApp Group dalam bentuk gambar, video, dan suara. Seperti halnya yang dilakukan di salah satu TK Negeri Kabupaten Pasuruan. TK tersebut juga menggunakan media pembelajaran berupa WhatsApp untuk memperlancar proses pembelajaran. Setiap hari sabtu orang tua mengambil tugas yang harus dikerjakan selama satu minggu kemudian tugas tersebut dikirim lewat group WhatsApp baik dalam bentuk gambar, video, atau rekam suara. Akan tetapi dengan media yang seperti itu dirasa kurang efektif karena guru tidak bisa komunikasi dan melihat secara langsung kegiatan siswa dalam mengerjakan tugas. Selain itu, siswa tidak berkomunikasi langsung dengan siswa lainnya sehingga menyebabkan antar siswa tidak saling mengenal. Hal tersebut sejalan dengan pendapat Bukidz (2019) bahwa siswa secara efektif dapat berpartisipasi dalam pembelajaran daring dengan guru melalui aktifitas video confrerence secara live dan sesuai dengan waktu yang telah disepakati.

Gambar berikut merupakan pembelajaran yang dilakukan oleh guru TK dan siswa dengan media WhatsApp. 


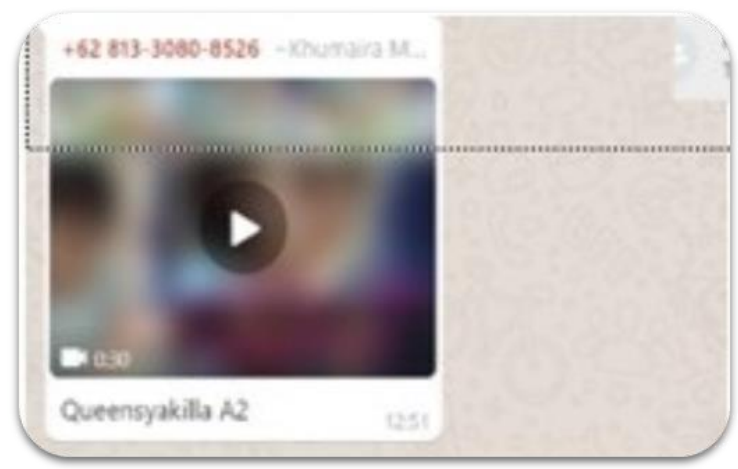

Gambar 1. Tugas Siswa dalam bentuk video

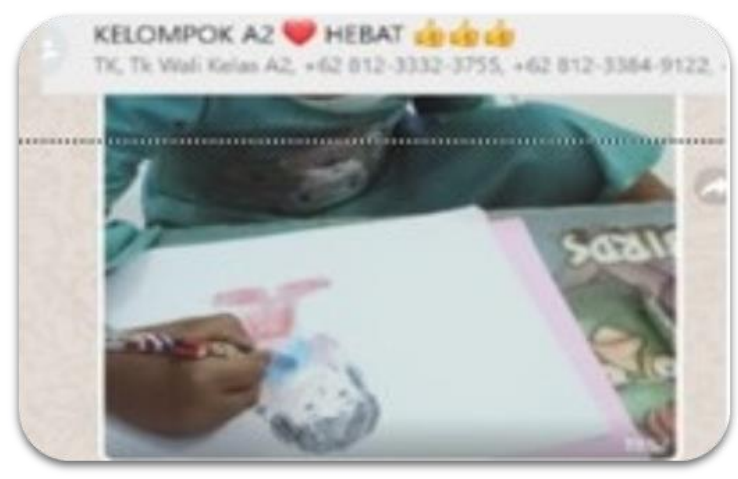

Gambar 2. Tugas Siswa dalam bentuk gambar

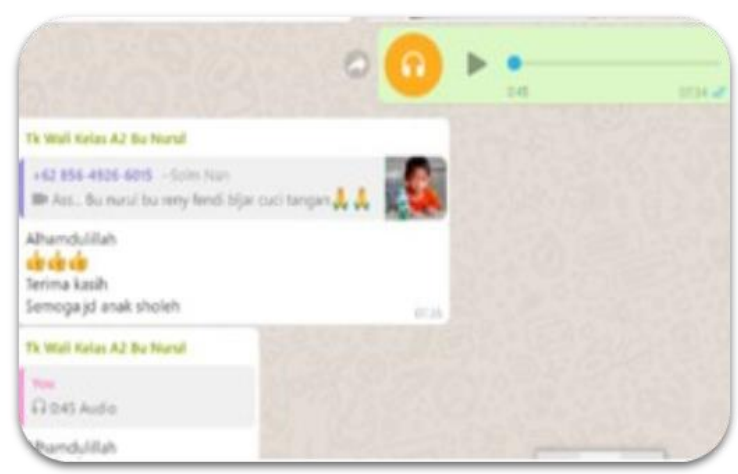

Gambar 3. Tugas Siswa dalam bentuk rekam suara

Agar guru dapat melakukan tatap muka langsung dengan siswa serta dapat mengetahui kegiatan yang dikerjakan siswa, pembelajaran secara daring dapat menggunakan aplikasi Zoom Cloud Meeting meskipun tatap muka secara virtual. Selain itu Zoom Cloud Meeting juga dapat digunakan dalam acara rapat serta pertemuan lainnya yang dilaksanakan secara online. Zoom Cloud Meeting adalah sebuah aplikasi yang dapat menunjang kebutuhan komunikasi di manapun dan kapanpun dengan banyak orang tanpa harus bertemu fisik secara langsung (Sahidillah \& Miftahurrisqi, 2011; Kurniawati et al., 2019). 
Aplikasi ini untuk video conference, dengan mudah dapat di install pada perangkat seperti: PC (Personal Computer) dengan webcame, Laptop dengan webcamera, dan Smartphone Android. Berdasarkan hasil observasi menunjukkan bahwa masih banyak guru TK tersebut yang belum mampu mengoperasikan aplikasi Zoom Cloud Meeting. Misalnya cara membuat jadwal rapat/pertemuan share jadwal rapat/pertemuan dan lain-lain. Oleh karena itu, perlu dilakukan pelatihan bagi guru TK dalam penggunaan aplikasi Zoom Cloud Meeting untuk memudahkan guru dalam proses pembelajaran secara daring maupun kegiatan-kegiatan lain yang dilaksanakan secara daring.

\section{METODE PELAKSANAAN}

Kegiatan Program Pengabdian Masyarakat (PPM) ini menggunakan metode dalam bentuk pelatihan yang dilakukan secara daring. Pengabdian ini dilaksanakan di TK Negeri Pembina Bangil pada tanggal 21 Agustus 2020. Pelatihan diikuti oleh 6 peserta yang merupakan guru TK Negeri Pembina. Adapun kegiatan yang dilaksanakan mulai dari analisis kebutuhan sampai pada solusi yang ditawarkan untuk mengatasi permasalahan tersebut. Adapun persoalan mitra dan solusi yang ditawarkan tercantum dalam Tabel 1.

Pada akhir pelatihan penggunaan aplikasi pembelajaran berbasis daring (Zoom Cloud Meeting) untuk guru TK dilakukan diskusi terkait dengan hal-hal dalam penggunaan aplikasi tersebut, yaitu mendaftar/login pada zoom, membuat jadwal meeting, membagikan jadwal meeting ke peserta, dan menghubungkan zoom pada YouTube.

Evaluasi keberhasilan dari program pengabdian masyarakat ini adalah $70 \%$ anggota mitra (dalam hal ini adalah guru TK negeri Pembina Bangil sebagai peserta) dapat mengoperasikan aplikasi Zoom Cloud Meeting yang meliputi cara daftar, login, membuat jadwal meeting, membagikan jadwal rapat/pertemuan dan menghubungkan Zoom pada YouTube.

Tabel 1. Persoalan Mitra dan Solusi yang ditawarkan

\begin{tabular}{|c|c|}
\hline Persoalan Mitra & Solusi yang ditawarkan \\
\hline $\begin{array}{l}\text { Belum mahir menggunakan aplikasi } \\
\text { Zoom Cloud Meeting }\end{array}$ & $\begin{array}{l}\text { Memberikan pelatihan penggunaan aplikasi Zoom } \\
\text { Cloud Meeting agar bisa bertindak sebagai host di } \\
\text { aplikasi Zoom Cloud Meeting }\end{array}$ \\
\hline $\begin{array}{l}\text { Belum bisa cara login dalam aplikasi } \\
\text { Zoom Cloud Meeting }\end{array}$ & $\begin{array}{l}\text { Memberikan pelatihan cara daftar dan login dalam } \\
\text { aplikasi Zoom Cloud Meeting agar bisa } \\
\text { melakukan kegiatan }\end{array}$ \\
\hline $\begin{array}{l}\text { Belum bisa membuat jadwal untuk } \\
\text { kegiatan meeting (pembelajaran } \\
\text { daring, rapat dan lainnya) }\end{array}$ & $\begin{array}{l}\text { Memberikan pelatihan cara membuat jadwal } \\
\text { rapat/pertemuan agar dapat melakukan rapat, } \\
\text { pertemuan dengan orang tua, pembelajaran siswa } \\
\text { melalui daring }\end{array}$ \\
\hline $\begin{array}{l}\text { Belum bisa share/membagikan link } \\
\text { untuk kegiatan rapat/pertemuan }\end{array}$ & $\begin{array}{l}\text { Memberikan pelatihan cara share link jadwal } \\
\text { rapat/pertemuan pada peserta dengan benar }\end{array}$ \\
\hline $\begin{array}{l}\text { Belum bisa menghubungkan zoom } \\
\text { pada youtube untuk acara-acara } \\
\text { webinar }\end{array}$ & $\begin{array}{l}\text { Memberikan pelatihan cara menghubungkan } \\
\text { zoom pada YouTube agar dapat mengadakan } \\
\text { webinar ketika diperlukan }\end{array}$ \\
\hline
\end{tabular}




\section{HASIL DAN PEMBAHASAN}

Dalam kegiatan pengabdian pada masyarakat (PPM) melalui pelatihan penggunaan aplikasi berbasis daring untuk guru TK di daerah Kabupaten Pasuruan. Kegiatan yang telah dilakukan dalam pelatihan tersebut yang didasarkan pada analisis situasi adalah sebagai berikut:

1. Penyusunan buku panduan penggunaan aplikasi Zoom Cloud Meeting.

Buku panduan dengan judul "Buku Panduan Penggunaan Aplikasi Zoom Cloud Meeting" ini telah selesai disusun. Buku panduan tersebut digunakan untuk memandu peserta pelatihan dalam menggunakan aplikasi Zoom Cloud Meeting yang meliputi cara daftar, login, membuat jadwal rapat/pertemuan, share jadwal meeting, dan menghubungkan Zoom pada YouTube. Dalam pelaksanaan pelatihan yang dilakukan secara daring, buku panduan telah dibagikan kepada guru peserta pelatihan dan telah diterapkan dengan baik.

\section{Pelaksanaan Pelatihan}

Pelatihan dilaksanakan di TK Negeri Pembina Bangil (secara daring) pada tanggal 21 Agustus 2020 mulai dari 08.00 sampai 10.00 WIB, dalam kegiatan tersebut meliputi penyampaian materi dan praktek. Adapun materi yang disampaikan terkait tentang cara daftar Zoom, Login, membuat jadwal rapat/pertemuan, Share/membagikan jadwal rapat/pertemuan, dan menghubungkan Zoom ke YouTube.

Setelah pelaksanaan pelatihan selesai, peserta (guru) diberikan angket mengenai ketercapaian tujuan kegiatan serta pesan kesan terhadap kegiatan tersebut. Dari angket tersebut dapat diketahui bahwa para peserta kegiatan sudah mampu mengoperasikan penggunaan aplikasi Zoom Cloud Meeting.

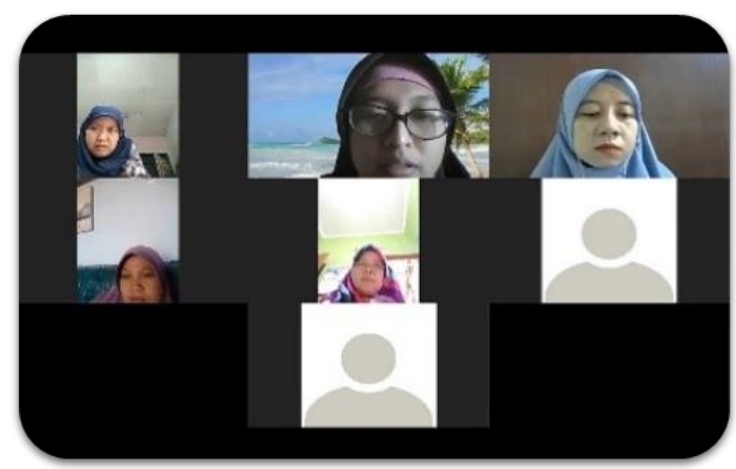

Gambar 4. Peserta Pelatihan 


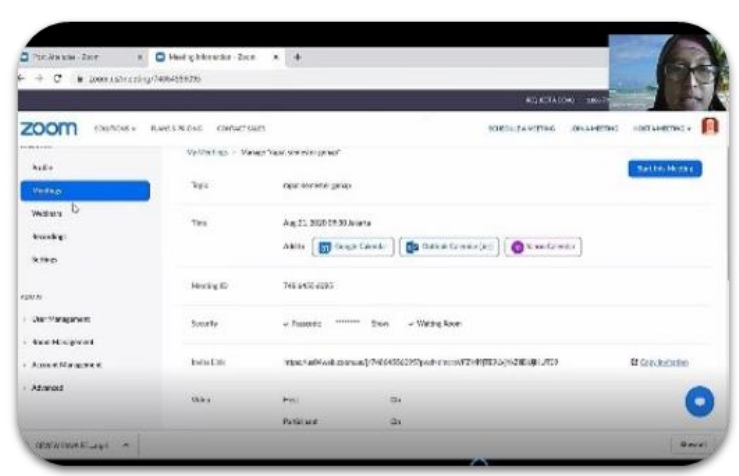

Gambar 5. Penyampaian materi oleh nara sumber

\section{Evaluasi Kegiatan}

Pelatihan merupakan pemberian pembelajaran secara nyata melalui latihan yang berulang-ulang dilapangan dengan bimbingan guru atau mentor. Metode yang diberikan memberikan kesempatan kepada peserta untuk mengekplorasi kemampuan dasar yang dimiliki, dalam hal ini peserta belajar mengoperasikan penggunaan aplikasi Zoom untuk menunjang semua aktifitas yang dilakukan secara daring. Seperti yang telah diungkapkan oleh (Dewi \& Handayani, 2020), metode latihan merupakan cara mengajar dengan memberikan latihan-latihan secara berulang-ulang mengenai apa yang telah diajarkan guru sehingga siswa memperoleh pengetahuan dan keterampilan tertentu.

Kemampuan peserta dalam melakukan pelatihan didasarkan pada indikator yang sebelumnya ditentukan oleh pelaksana pengabdian. Adapun indikator yang dimaksud terlihat pada Tabel 2 sebagai berikut.

Tabel 2. Indikator Kemampuan Peserta Mengoperasikan Aplikasi Zoom

\begin{tabular}{cl}
\hline $\begin{array}{c}\text { No. } \\
\text { Indikator }\end{array}$ & Indikator \\
\hline 1 & Mampu melakukan daftar di aplikasi Zoom \\
2 & Mampu melakukan login di aplikasi Zoom \\
3 & Mampu membuat jadwal rapat/pertemuan di aplikasi Zoom \\
4 & Mampu share jadwal rapat/pertemuan pada peserta di aplikasi Zoom \\
5 & Mampu menghubungkan Zoom pada YouTube \\
\hline Note: Indikator Kemampuan Peserta
\end{tabular}

Berdasarkan indikator tersebut, peserta dinilai kemampuannya dalam mengoperasikan aplikasi Zoom Cloud Meeting. Hasil yang telah didapat kemudian dianalisa kemampuannya sesuai dengan Gambar 6 sebagai berikut. Berdasarkan grafik tersebut terlihat peningkatan kemampuan peserta dalam mengoperasikan aplikasi Zoom Cloud Meeting. 


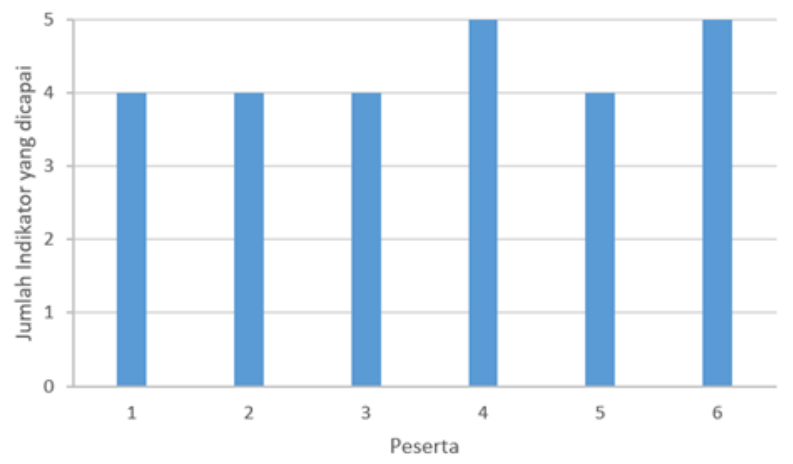

Gambar 6. Hasil kemampuan peserta pelatihan

Berdasarkan Gambar 6 di atas menunjukkan bahwa hasil kemampuan peserta pelatihan dapat dikatagorikan menjadi 2, yaitu peserta yang berhasil mencapai 5 indikator $(100 \%$ bisa) dengan jumlah 2 peserta dan peserta yang mencapai 4 indikator $(80 \%$ bisa) dengan jumlah 4 peserta dalam penggunaan aplikasi Zoom Cloud Meeting. Dari pelatihan ini peserta sangat terbantu karena sebelumnya peserta belum mampu mengoperasikan aplikasi Zoom Cloud Meeting tetapi setelah pelatihan peserta menjadi mampu mengoperasikan aplikasi Zoom Cloud Meeting.

\section{KESIMPULAN}

Berdasarkan kegiatan pengabdian pada masyarakat (PPM) ini, dapat disimpulkan bahwa peserta (yaitu guru TK) sudah mampu mengoperasikan aplikasi Zoom Cloud Meeting, meliputi cara daftar, login, membuat jadwal rapat/pertemuan, share jadwal rapat/pertemuan, dan menghubungkan Zoom pada YouTube. Kegiatan pengabdian ini direspon dengan baik dan disarankan untuk mengadakan kegiatan pengabdian selanjutnya.

Setelah pelatihan pengabdian ini perlu dikembangkan kemampuan lainnya dalam mengoperasikan aplikasi Zoom Cloud Meeting. Misalnya membagi room dalam aplikasi Zoom sehingga akan mempermudah pembagian kelompok dalam proses pembelajaran (pembagian kelas bermain, yaitu Kelas A, Kelas B, dan sebagainya dalam waktu yang bersamaan). Dengan adanya pelatihan ini diharapkan dapat meningkatkan keterampilan guru pada proses pembelajaran dengan memanfaatkan IT (Information Technology).

\section{UCAPAN TERIMA KASIH}

Ucapan terimakasih disampaikan kepada TK Negeri Pembina Kabupaten Pasuruan yang telah memberikan ijin untuk melakukan pengabdian masyarakat sehingga kegiatan ini dapat terlaksana dengan lancer.

\section{DAFTAR RUJUKAN}

Bukidz, D. P. (2019). Manajemen Pengetahuan Dalam Pembelajaran Daring di UPH Kampus Medan. Journal of Accounting \& Management Innovation, $3(2)$,

170-185. 
https://ejournal.medan.uph.edu/index.php/jam/article/view/446

Dewi, T. U., \& Handayani, S. L. (2020). Pelatihan Pembuatan Soal Berbasis Digital Bagi Guru SMA di Era Revolusi Industri 4.0. Jurnal Inovasi Hasil Pengabdian Masyarakat (JIPEMAS), 3(2), 146-153. https://doi.org/10.33474/jipemas.v3i2.6697

Firman, \& Rahayu, S. (2020). Pembelajaran Online di Tengah Pandemi Covid19. Indonesian Journal of Educational Science (IJES), 2(2), 81-89. https://doi.org/10.31605/ijes.v2i2.659

Iftakhar, S. (2016). Google classroom: what works and how? Journal of Education and Social Sciences, 3, 12-18.

Korucu, A., \& Alkan, A. (2011). Differences between m-learning ( mobile learning ) and e-learning, basic terminology and usage of m-learning in education. Procedia - Social and Behavioral Sciences, 15, 1925-1930. https://doi.org/10.1016/j.sbspro.2011.04.029

Kurniawati, E., Santoso, A., \& Widowati, S. Y. (2019). Pelatihan Pemasaran Online Bagi Kelompok Usaha Bersama (KUB) "SRIKANDI". Jurnal Inovasi Hasil Pengabdian Masyarakat (JIPEMAS), 2(2), 132-138. https://doi.org/10.33474/jipemas.v2i2.2722

Lestari, N., \& Wirasty, R. (2019). Pemanfaatan multimedia dalam media pembelajaran interaktif untuk meningkatkan minat belajar siswa. Amaliah: Jurnal Pengabdian Kepada Masyarakat, 3(2).

Noor, I. H. (2011). Pemanfaatan Ilmu Pengetahuan dan Teknologi dalam Kegiatan Pengabdian Masyarakat di Perguruan Tinggi. Jurnal Pendidikan Dan Kebudayaan, 17(3), 306-315. https://doi.org/10.24832/jpnk.v17i3.27

Puspitasari, N. A., \& Hidayatullah, S. (2020). Peningkatan wawasan penerapan model pembelajaran berorientasi HOTS (Higher Order Thinking Skill) bagi guru MTs dan MA. Jurnal Inovasi Hasil Pengabdian Masyarakat (JIPEMAS), 3(2), 128-135. https://doi.org/10.33474/jipemas.v3i2.6131

Sahidillah, M., \& Miftahurrisqi, P. (2011). WhatsApp Sebagai Media Literasi Digital Siswa. Jurnal Varidika Kajian Penelitian Pendidikan, 3(1), 52-57. https://doi.org/10.23917/varidika.v1i1.8904

Sicat, A. S., \& Ed, M. A. (2015). Enhancing College Students 'Proficiency in Business Writing Via Schoology. International Journal of Education and Research, 3(1), 159-178. https://ijern.com/journal/2015/January2015/14.pdf

So, S. (2016). Mobile instant messaging support for teaching and learning in higher education. The Internet and Higher Education, 31, 32-42. https://doi.org/10.1016/j.iheduc.2016.06.001 